Louisiana State University

LSU Digital Commons

2-15-2018

\title{
Neutron interferometry detection of early crack formation caused by bending fatigue in additively manufactured SS316 dogbones
}

\author{
Adam J. Brooks \\ Louisiana State University \\ Daniel S. Hussey \\ National Institute of Standards and Technology \\ Hong Yao \\ Louisiana State University \\ Ali Haghshenas \\ Louisiana State University \\ Jumao Yuan \\ Louisiana State University
}

See next page for additional authors

Follow this and additional works at: https://digitalcommons.Isu.edu/chemistry_pubs

\section{Recommended Citation}

Brooks, A., Hussey, D., Yao, H., Haghshenas, A., Yuan, J., LaManna, J., Jacobson, D., Lowery, C., Kardjilov, N., Guo, S., Khonsari, M., \& Butler, L. (2018). Neutron interferometry detection of early crack formation caused by bending fatigue in additively manufactured SS316 dogbones. Materials and Design, 140, 420-430. https://doi.org/10.1016/j.matdes.2017.12.001

This Article is brought to you for free and open access by the Department of Chemistry at LSU Digital Commons. It has been accepted for inclusion in Faculty Publications by an authorized administrator of LSU Digital Commons. For more information, please contact ir@lsu.edu. 


\section{Authors}

Adam J. Brooks, Daniel S. Hussey, Hong Yao, Ali Haghshenas, Jumao Yuan, Jacob M. LaManna, David L. Jacobson, Caroline G. Lowery, Nikolay Kardjilov, Shengmin Guo, Michael M. Khonsari, and Leslie G. Butler 


\title{
Neutron Interferometry Detection of Early Crack Formation Caused by Bending Fatigue in Additively Manufactured SS316 Dogbones
}

Adam J. Brooks ${ }^{\mathrm{a}, *}$, Daniel S. Hussey ${ }^{\mathrm{b}}$, Hong Yao ${ }^{\mathrm{c}}$, Ali Haghshenas ${ }^{\mathrm{c}}$, Jumao Yuan ${ }^{\mathrm{a}}$, Jacob M. LaManna ${ }^{\mathrm{b}}$, David L. Jacobson ${ }^{b}$, Caroline G. Lowery ${ }^{\mathrm{a}}$, Nikolay Kardjilov ${ }^{\mathrm{d}}$, Shengmin Guo ${ }^{\mathrm{c}}$, Michael M. Khonsari ${ }^{\mathrm{c}}$, Leslie G. Butler ${ }^{\mathrm{a}}$

${ }^{a}$ Department of Chemistry, Louisiana State University, Baton Rouge, LA 70803, USA

${ }^{b}$ National Institute of Standards and Technology, 100 Bureau Dr., Mail Stop 8461, Gaithersburg, MD 20899-8461

${ }^{c}$ Department of Mechanical and Industrial Engineering, Louisiana State University, Baton Rouge, LA 70803, USA

${ }^{d}$ Helmholtz Center Berlin for Materials and Energy, 14109 Berlin, Germany

\begin{abstract}
Fatigue in selective laser melted (SLM) and conventionally manufactured stainless steel (SS) 316 dogbones was studied with neutron imaging methods for attenuation, diffraction, and scattering. Neutron attenuation tomography and Bragg edge imaging did not reveal crack formation. Conversely, to efficiently detect the microcrack evolution, two methods of grating-based neutron interferometry, Talbot-Lau and far-field, were employed. Both interferometry methods detect early crack formation via the dark-field (scattering) images, especially for porous microstructures in the range of $0.6 \mu \mathrm{m}$ to $2 \mu \mathrm{m}$. The dark-field image combines sensitivity to micrometer-sized scattering centers at crack formation with sub-millimeter imaging resolution. The crack formation observed with neutron interferometry dark-field was validated post-imaging with additional fatigue cycles to fracture. Further inspection was performed by scanning electron microscopy (SEM) and optical photography. In the two fatigued dogbones, SLM and conventional crack formation was identified to within $1 \mathrm{~mm}$.
\end{abstract}

Keywords: additive manufacturing, neutron interferometry, Bragg edge spectroscopy, fatigue

${ }^{*}$ Corresponding author: Adam J. Brooks, Abroo38@ @ 1su.edu 


\section{Introduction}

Additive manufacturing (AM) of metals has gained recent traction in many industrial fields. In particular, the stainless steel alloy 316 (SS316) is an austenitic steel that has properties of good ductility, a low deformation rate during cooling, and easy manipulation (bending or stretching) [1]. While there are many advantages to SS316, one common problem is fatigue, where thermal fatigue damage can be seen from a network of surface cracks propagating throughout the sample [2]. Grain size can also play a detrimental role in stainless steel parts with a reduced fatigue life from chromium carbide precipitation and inter-granular corrosion [3]. With tension-compression fatigue tests, it is possible to observe mechanical property changes, estimate fatigue damage in the microstructure, and determine the remaining lifetime of conventional and AM stainless steel dogbone samples [4, 5].

While there are many different AM methodologies, selective laser melting (SLM) is a key AM technology capable of producing complex three dimensional (3D) metallic parts with a wide range of applicability [6]. For SLM, multiple laser line scans (molten tracks) form the desired two dimensional (2D) section shape and then multiple powder deposition/laser-irradiation cycles generate complex 3D metal/alloy parts. During the SLM process, upon laser irradiation, the powder material is heated so that it melts and forms a liquid pool. Afterwards, the molten pool solidifies and cools quickly. Due to fast heating, melting and solidification, and multiple passes of laser scans, as-fabricated SLM parts usually contain residual stress. Defects such as a lack of fusion [7] or porosity are likely the result of the process being highly stochastic and highly non-equilibrium, which create concerns for weaker mechanical strength and shorter service life.

One way to observe these defects in a non-destructive manner is through imaging [8]. X-ray imaging, diffraction, and microscopy have shown great promise in visualizing steel and titanium pores from tensile stress damage [9, 10, 11]. Related experiments with neutron sources have employed diffraction [12], diffraction contrast imaging [13, 14], residual stress imaging [15, 16, 17], and dark-field imaging [18, 19].

Two techniques are under development for the non-destructive imaging of AM parts. Neutron Bragg edge imaging has been used for mapping torsional strain in conventional samples and could be optimized for large AM printed parts [20, 21, 22]. Recent achievements in observing sub-micron features with a large field-ofview have been possible via grating-based interferometry [23]. Of the attenuation, differential phase contrast and dark-field datasets generated through grating-based interferometry, the dark-field modality, which is synonymous with small angle scattering, has shown the most promise [18]. The grating-interferometry instrumentation setup currently designed for Talbot-Lau interferometry only has the ability to probe a small range of autocorrelation scattering lengths, $\xi$. Under development, another grating-based imaging technique called far-field interferometry [24] can be optimized for AM samples. Originally realized for X-ray systems [25], the benefits of the far-field setup with neutrons include the use of two phase gratings for high flux, high sensitivity to small angle scattering, and the ability to probe a wide range of autocorrelation lengths [24]. By scanning a range of autocorrelation lengths, information is obtained for the size, shape, and volume fraction of scattering centers [26], where scattering may come from pores or precipitates within the AM sample [27, 7].

This report describes a search for non-destructive neutron imaging methods for observing fatigue and failure in SS316 dogbones prepared conventionally and with selective laser melting additive manufacturing. 
If one could pin-point the evolution of internal microstructure failure in an AM SS316 sample without destruction, this would be very beneficial to the AM community. Prior to imaging, some dogbones were fatigued by bending to fracture or to half of the fatigue cycles required to fracture. To examine crystal grain structure at fracture and stress regions, neutron Bragg edge imaging was performed. To examine the microcracks at the fracture and stressed regions, neutron Talbot-Lau interferometry imaging was performed at a set autocorrelation length. Lastly, far-field interferometry was utilized to probe scattering features over a wide range of autocorrelation lengths. The AM parts reported in this paper are as-fabricated samples, where future research can be conducted on heat treated AM parts. The results show, in broad terms, the utility of neutron imaging to examine fatigue in conventional SS316 and SLM AM. In particular, darkfield interferometry at autocorrelation lengths near $1 \mu \mathrm{m}$ may show the initial formation and evolution of microcracks under bending fatigue testing.

\section{Experimental}

The following section describes background into the SLM process and imaging theory to help with the analysis of the results.

\subsection{Materials and Specimens}

Bending tests are performed on both machined and SLM SS316 specimens (compositions and material properties are shown in Tables 1 and 21 Figure 1. The dimensions of the specimens are recommended by the manufacturer of the fatigue bending apparatus, which are according to ASTM STP 566 [28]. The SLM and the conventionally manufactured specimens are polished longitudinally up to P2000 to eliminate any depression and/or elevation on the surface for all of them to be in the same condition. The SS316 powder is non-magnetic, indicative that any scattering observed during imaging is likely from porosity and not magnetic domains [29].

Table 1: Compositions of conventional and SLM SS316 samples by percent weight

\begin{tabular}{|l|c|c|c|c|c|c|c|c|c|c|c|c|}
\hline $\begin{array}{l}\text { Element } \\
\text { Symbol }\end{array}$ & $\mathbf{C r}$ & $\mathbf{N i}$ & $\mathbf{C}$ & $\mathbf{M n}$ & $\mathbf{C u}$ & $\mathbf{M o}$ & $\mathbf{S i}$ & $\mathbf{S}$ & $\mathbf{P}$ & $\mathbf{N}$ & $\mathbf{T i}$ & $\mathbf{F e}$ \\
\hline $\begin{array}{l}\text { SLM } \\
(\%)\end{array}$ & $16.5-18.5$ & $10.0-13.0$ & $0-0.030$ & $0-2.0$ & -- & $2.0-2.5$ & $0-1.0$ & $0-0.030$ & $0-0.045$ & -- & - & Balance \\
\hline $\begin{array}{l}\text { Conv. } \\
(\%)\end{array}$ & $16-18.5$ & $10-15.0$ & $0-0.08$ & $0-2.0$ & $0-1.0$ & $0-3.0$ & $0-1.0$ & 0.35 & $0-0.045$ & $0-0.1$ & 0.7 & Balance \\
\hline
\end{tabular}

Commercial stainless steel plates of $3 \mathrm{~mm}$ thickness were used to machine dogbone samples (Fig. 1). A Concept Laser Mlab-cusing-R SLM system was used in this study to prepare rectangular shaped plates with a thickness of $3 \mathrm{~mm}$. Austenitic stainless steel 316L powders from Concept-Laser (CL 20ES) were used with Concept-Laser's "Speed-cusing" processing parameters. Upon creation of a computer aided design model

\footnotetext{
${ }^{1}$ CL20-ES, www.concept-laser.de

${ }^{2}$ Certain trade names and company products are mentioned in the text or identified in an illustration in order to adequately specify the experimental procedure and equipment used. In no case does such identification imply recommendation or endorsement by the National Institute of Standards and Technology, nor does it imply that the products are necessarily the best available for the purpose.
} 


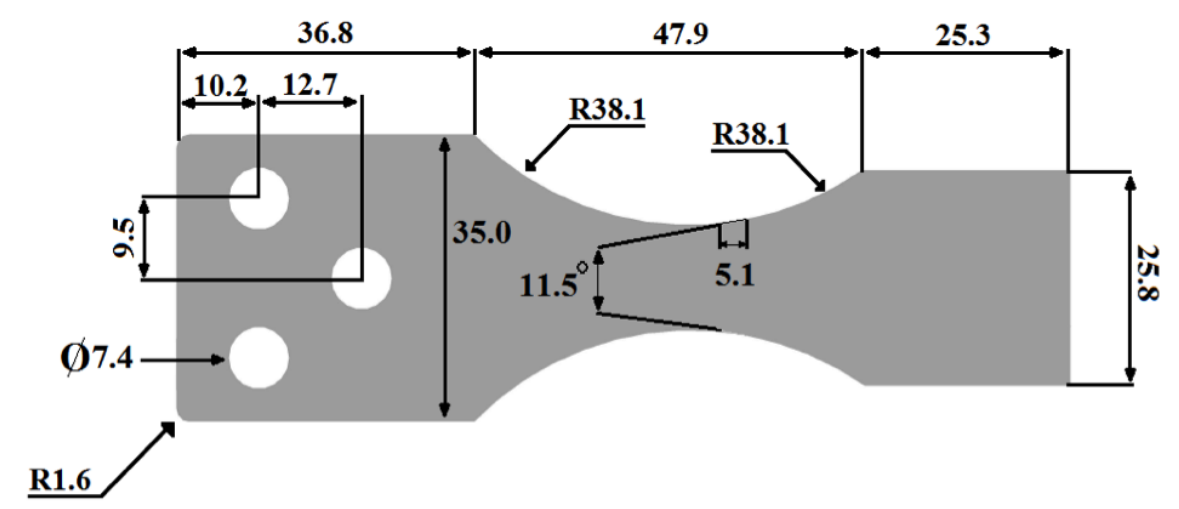

Figure 1: Schematic illustration of a flat dogbone specimen. All dimensions are in millimeters.

of the desired geometry, two-dimensional slice and support structure information is created by AutoFab software for input into the Mlab system. During the building process, the Mlab system is purged with argon (Ar) down to an oxygen level less than $0.7 \%$ by volume. For each layer, after lowering the building platform by $25 \mu \mathrm{m}$, a re-coater blade moves across the build platform and deposits an even layer of SS 316L powder onto the build platform. After the rectangular plates were built, a wire electron discharging machine (EDM) (Mitsubishi MV series) was used to cut out the dogbone samples, Fig. 1. per ASTM E8/E8M-16a.

\subsection{Fatigue Testing}

Fully-reversed cyclic bending fatigue tests are performed using a laboratory apparatus manufactured by Fatigue Dynamics, Inc. (Michigan, USA) and according to the Handbook of Fatigue Testing [28]. It is a compact, bench-mounted unit with a variable speed motor (the load frequency is adjustable) that actuates a crank connected to the reciprocating platen, and a cycle counter shows the number of cycles of the cyclic load. The actuated crank is adjusted by choosing a constant strain value on the pulley connected to the end of the crank which determines the load level applied to the specimen in the form of bending force.

First, experiments are performed to determine the fatigue life of both types of specimens at a certain stress level (500 MPa). $500 \mathrm{MPa}$ stress was calculated from $11.43 \mathrm{~mm}$ movement of the dogbones via a displacement machine. Also, $500 \mathrm{MPa}$ is beyond the yield stress in both samples (Table 2). At this stress level, the fatigue life for both specimens is found to be nearly the same $(60,000$ cycles). Then, fatigue tests are performed at the same stress level with interruption at half-life of the specimens to examine their internal

Table 2: Mechanical properties of conventional and SLM SS316 samples

\begin{tabular}{|l|c|c|c|c|c|}
\hline $\begin{array}{l}\text { Mechanical } \\
\text { Properties }\end{array}$ & $\begin{array}{c}\text { Yield } \\
\text { Strength }\end{array}$ & $\begin{array}{c}\text { Tensile } \\
\text { Strength }\end{array}$ & Hardness & Construction & $\begin{array}{c}\text { Material } \\
\text { Condition }\end{array}$ \\
\hline SLM (\%) & $470 \mathrm{MPa}$ & $570 \mathrm{MPa}$ & $98 \mathrm{HRB}(20 \mathrm{HRC})$ & SLM & Unannealed \\
\hline Conv. (\%) & $206 \mathrm{MPa}$ & $515 \mathrm{MPa}$ & $93 \mathrm{HRB}(13 \mathrm{HRC})$ & Cold Rolled & Annealed \\
\hline $\begin{array}{l}\text { Mechanical } \\
\text { Properties }\end{array}$ & $\begin{array}{c}\text { Nominal } \\
\text { Density }\end{array}$ & $\begin{array}{c}\text { Modulus of } \\
\text { Elasticity }\end{array}$ & Elongation & $\begin{array}{c}\text { Thermal } \\
\text { Conductivity }\end{array}$ & $\begin{array}{c}\text { Melting } \\
\text { Range }\end{array}$ \\
\hline SLM (\%) & -- & $200 \mathrm{GPa}$ & $>15 \%$ & $8.3 \mathrm{~W} / \mathrm{m}$ & -- \\
\hline Conv. (\%) & $8030 \mathrm{~kg} / \mathrm{m}^{3}$ & $196 \mathrm{GPa}$ & $10 \%-69 \%$ & $8.1 \mathrm{~W} / \mathrm{m}-9.1 \mathrm{~W} / \mathrm{m}$ & $1371.1^{\circ} \mathrm{C}-1482.2^{\circ} \mathrm{C}$ \\
\hline
\end{tabular}


microstructure characteristics. The three conventional and three AM dogbones are referred to as pristine, half-life, and fractured for the following.

\subsection{Neutron Tomography, Interferometry, and Bragg Edge Spectroscopy (HZB CONRAD2)}

Conventional neutron attenuation tomography, Bragg edge spectroscopy, and grating-based interferometry were performed on the conventional and AM dogbones at the HZB CONRAD2 imaging beamline [30, 31]. The beamline operated with an aperture of $3 \mathrm{~cm}$ providing neutron fluence rate of $2.4 \times 10^{7} \mathrm{~cm}^{-2} \mathrm{~s}^{-1}$ at the detector (5 m, L/D value of 167). A $100 \mu \mathrm{m}$ thick ${ }^{6} \mathrm{LiF} / \mathrm{ZnS}$ scintillator was used to convert neutron flux into visible light. An Andor Ikon L-936 camera (2048×2048 pixels) was used for imaging. For the neutron attenuation tomography, all six dogbones mounted together and separated by aluminum spacers. Attenuation projections were measured over $180^{\circ}$ in $0.5^{\circ}$ increments. The projections were reconstructed in TomoPy with Gridrec and visualized in Avizo. For Bragg edge imaging, experiments required exposure times of 100 seconds with monochromatic beam from $0.2 \mathrm{~nm}$ to $0.45 \mathrm{~nm}$ with steps of $0.002 \mathrm{~nm}$. The monochromator bandpass was $\Delta \mathrm{E} / \mathrm{E} \approx 3 \%$. To improve the contrast-to-noise ratio, binning of $2 \times 2$ was performed.

Grating interferometry of $3 \mathrm{~mm}$ thick SS316 AM and conventional samples was also performed using 20 second exposures with the source grating, G0, stepped over $1.2 \mathrm{~mm}$ with 14 steps. Twenty images were collected at each grating step and the median value selected on a pixel-by-pixel basis. The effective pixel size was $30 \mu \mathrm{m}$ for interferometry. The source grating, G0, had a period of $790 \mu \mathrm{m}$ with $20 \mu \mathrm{m}$ Gd thickness, the phase grating, G1, a period of $7.96 \mu \mathrm{m}$ with $38 \mu \mathrm{m}$ thick Si for a $\pi$ phase shift at $0.35 \mathrm{~nm}$, and the analyzer grating, G2, a period of $4 \mu \mathrm{m}$ with $10 \mu \mathrm{m}$ thick Gd. The distance for G0-G2 was 4,500 mm, G1-G2 was $22.7 \mathrm{~mm}$ (1st Talbot distance for $0.35 \mathrm{~nm}$ ), and G2-detector distance was $4 \mathrm{~mm}$ [32].

\subsection{Far-Field Interferometry Radiography (NIST NG6)}

Far-field grating interferometry imaging experiments were performed at the NIST reactor, cold neutron imaging instrument (NG6) [33]. A sample setup of the far-field grating-based interferometry is shown in Fig. 2[24].

The beamline operated with an aperture of $1.5 \mathrm{~cm}$, allowing sufficient neutron fluence rate with a double monochromator, $5.0 \times 10^{5} \mathrm{~cm}^{-2} \mathrm{~s}^{-1}$ at the detector $\approx 9 \mathrm{~m}$ downstream at a wavelength, $\lambda$, of $0.54 \mathrm{~nm}$. An Andor Neo sCMOS camera $(2160 \times 2560$ pixels, pixel size $6.5 \mu \mathrm{m})$ cooled to $-30{ }^{\circ} \mathrm{C}$ was used for imaging. The camera was optically coupled with a reproduction ratio of 4.3 to a $20 \mu \mathrm{m}$ thick gadolinium oxysulfide (GadOx) scintillator $\left(7.6 \mathrm{mg} / \mathrm{cm}^{2}\right.$ Gadox:Tb). The effective pixel size was $28 \mu \mathrm{m}$ and $120 \mathrm{~s}$ exposures provided enough neutron flux to observe fringes. At each grating step, three images were acquired and the median value selected on a pixel-by-pixel basis.

The interferometer was operated in stepped-grating mode, typically with nine G1 positions evenly spaced over $3 \mu \mathrm{m}$, slightly more than the $2.4 \mu \mathrm{m}$ periods, $p_{g}$, of G1 and G2. The period of the source grating, $\mathrm{p}_{s}$, was $354 \mu \mathrm{m}$. The total length of the system, L, was $4.6 \mathrm{~m}$. For radiography, the sample was first imaged with a sample-to-detector distance, $z$, of $1.58 \mathrm{~m}$. After a sample was imaged in one location, the sample was translated towards the detector by 5 steps of $275 \mathrm{~mm}$ or 13 steps of $91.66 \mathrm{~mm}$ dependent upon the experiment. 


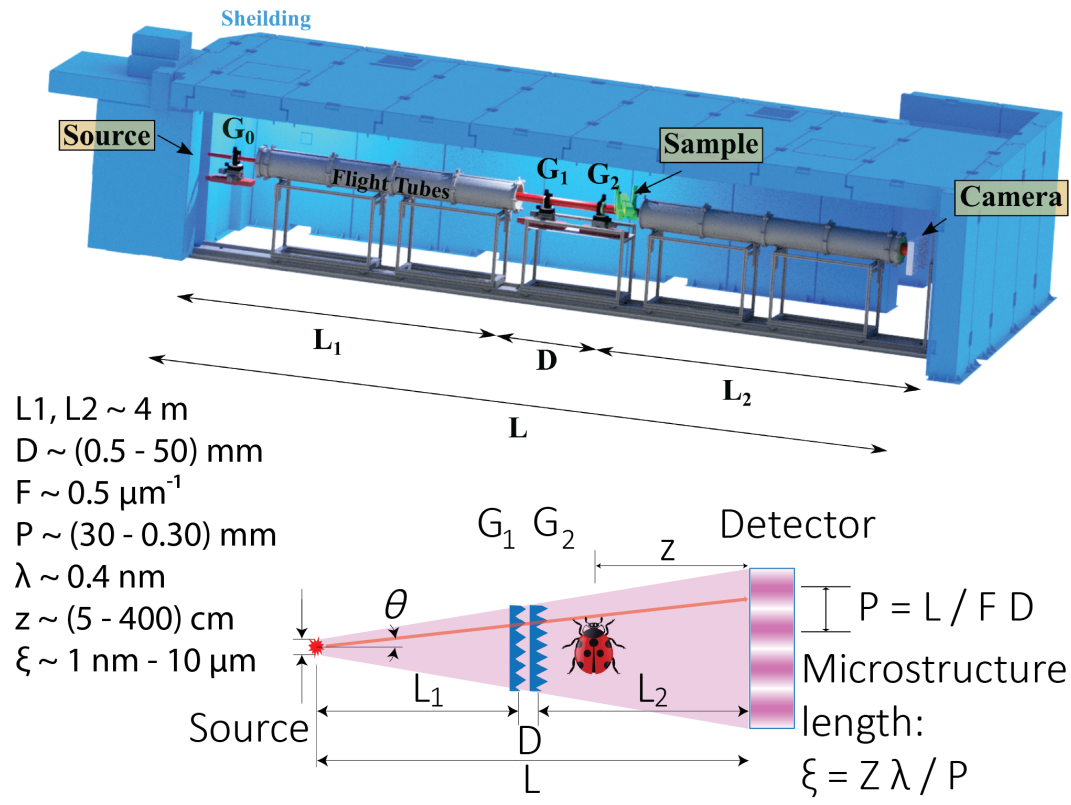

Figure 2: A sketch shows one of two setups used for far-field interferometry at NIST NG6. $\lambda=0.54 \mathrm{~nm}, \mathrm{D}=26 \mathrm{~mm}, L_{1}=L_{2}=$ $2.3 \mathrm{~m}, \mathrm{~L}=4.6 \mathrm{~m}, \mathrm{z}$ ranges from $0.48 \mathrm{~m}$ to $1.58 \mathrm{~m}, \mathrm{p}_{s}=354 \mu \mathrm{m}$, and $\mathrm{p}_{g}$ for $\mathrm{G}_{1}, \mathrm{G}_{2}=2.4 \mu \mathrm{m}$.

\subsection{Electron Microscopy Analysis}

The microstructure of the tested samples were examined using a field-emission scanning electron microscope, FE-SEM (FEI, Quanta 3DFEG), equipped with backscattering electron (BSE) and energy dispersive spectroscopy (EDS) detector at the LSU Shared Instrumentation Facility (SIF).

For SEM, small sections were cut out of the dogbone shaped samples using a diamond slow-saw and then mounted into epoxy resin (SamplKwick fast cure acrylic resin, produced by Buehler) for easy handing and retention. The targeted surfaces were subsequently ground by \#320, \#400, \#600, and \#800 grits of SiC sandpapers in sequence, before wet-polished with $6 \mu \mathrm{m}, 3 \mu \mathrm{m}, 1 \mu \mathrm{m}, 0.3 \mu \mathrm{m}$ and $0.05 \mu \mathrm{m} \mathrm{Al}_{2} \mathrm{O}_{3}$ suspensions. The polished samples were etched using Carpenter Stainless Steel Etchant (PACE Technologies). After immersing in etchant for 25 seconds at room temperature, the samples were immediately cleaned with water.

\subsection{Interferometry Data Analysis: Far-field and Talbot-Lau}

\subsubsection{Extracting Dark-Field (Scattering) Images from a Talbot-Lau or Far-Field Interferogram}

Shown in Fig. 3 is a nearly raw image; the image is computed from the median combination of three images in time and then a spatial median filter is applied. The image shows the projection attenuation of the dogbone affected by both interferometry fringes and geometric blur. The intensity of the fringe pattern evolves with the position of the stepped grating, as shown in Fig. 3 for far-field interferometry. The intensity, 

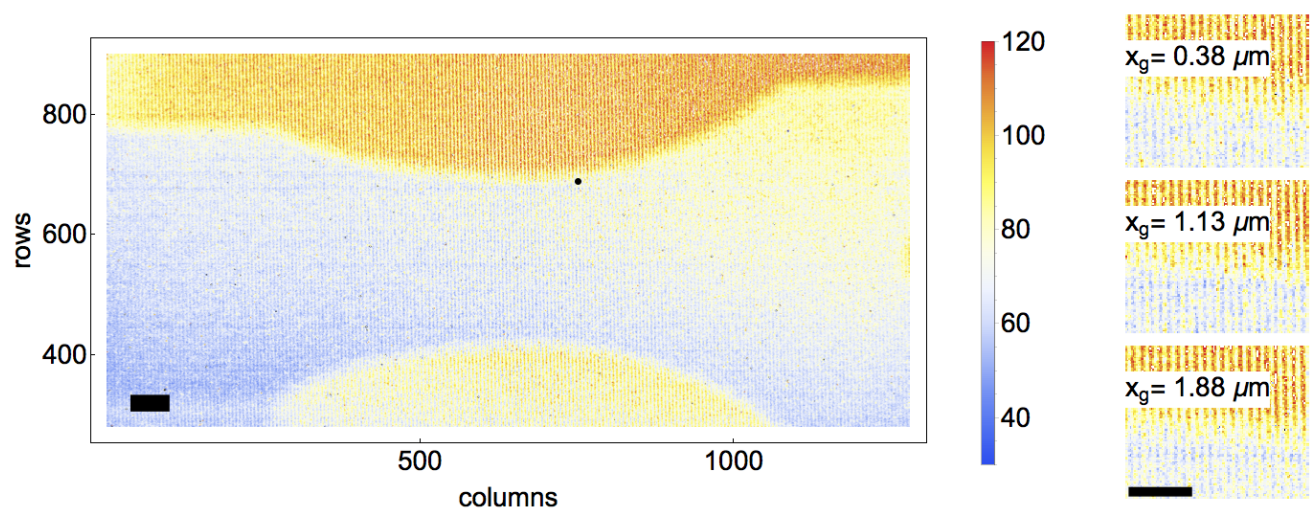

Figure 3: Full field-of-view image of AM half-life dogbone. The image processing has included dark count correction, median filtering of 3 images, all collected with $120 \mathrm{~s}$ exposure, and $2 \times 2$ binning with gaussian resampling. The test point is at (column=750, row 710 ). When expanded, views for a region centered below the test point can be observed. The fringes evolve with the horizontal stepping motion, $x_{g}$ ( Eq. 1 ) of the G1 phase grating. The sample-to-detector distance, $z$, is $0.477 \mathrm{~m}$. The scale bar is $1 \mathrm{~mm}$ long.

I, can be fitted with a cosine function [24] or its linear expansion [34]:

$$
\begin{aligned}
I\left(x_{g}\right) & =A+B \cos \left(\frac{2 \pi x_{g}}{p_{g}}+\phi\right) \\
I\left(x_{g}\right) & =A+\left[\sin \left(\frac{2 \pi x_{g}}{p_{g}}\right)\right] B_{\cos } \cos \phi+\left[\cos \left(\frac{2 \pi x_{g}}{p_{g}}\right)\right] B_{\sin } \sin \phi \\
\text { where } B & =\sqrt{B_{\cos }^{2}+B_{\text {sin }}^{2}}
\end{aligned}
$$

where $\phi$ is the phase of the beam, $x_{g}$ is the stepping motion of the grating, and $p_{g}$ is the period of the phase grating. The offset, $A$, and amplitude, $B$, of Eq. 1 are used to define the fringe visibility as visibility $=B / A$. The image modality called dark-field (DF) is the ratio of fringe visibility with the sample in the beam versus out of the beam:

$$
\text { dark-field }=\frac{\text { visibility }_{\text {sample }}}{\text { visibility }_{\text {reference }}}=\frac{B_{\text {sample }} / A_{\text {sample }}}{B_{\text {reference }} / A_{\text {reference }}}
$$

\subsubsection{Scattering Analysis for Non-Interacting Spherical Particles}

The DF image intensity has been correlated with scattering theory [26, 35, 36, 37, 38]

$$
D F=\exp \left[\int_{\text {path }} \Sigma\left[G\left(\xi_{\text {corr }}\right)-1\right] d t\right]
$$

where $t$ is sample thickness, $G\left(\xi_{\text {corr }}\right)$ is the pair-correlation function describing scattering. For a two-phase system

$$
\Sigma=(3 / 2)\left(1-\phi_{v}\right) \phi_{v} \Delta \rho^{2} \lambda^{2} r
$$


$\phi_{\nu}$ is the volume fraction of the scatterer, $\Delta \rho$ is the scattering length density contrast, $\lambda$ is the wavelength, and $\mathrm{r}$ is the radius of the scatterer. To simplify for fitting, we use the term A to represent the variables below.

$$
A=(3 / 2)\left(1-\phi_{v}\right) \phi_{v} \Delta \rho^{2} t
$$

resulting in

$$
-\ln (D F)=A \lambda^{2} r\left[1-G\left(\xi_{\text {corr }}\right)\right]
$$

In the case of SS316, $\Delta \rho=8.142 \times 10^{-4} / \mathrm{nm}^{2}$ based on the chemical formula by weight in Table 1 , the NIST neutron scattering length density calculator 3 , and the assumption of vacuum-filled pores. While there are many possible correlation functions [39], we have chosen to model the microstructure as dilute noninteracting spheres because the porosity of the SLM components is on the order of $0.1 \%$. The pair-correlation function for this system can be approximated as:

$$
G_{\text {sphere }}\left(\xi_{\text {corr }}\right) \approx \exp \left[-\frac{9}{8}\left(\frac{\xi_{\text {corr }}}{r}\right)^{2}\right]
$$

where $\xi_{\text {corr }}$ is the autocorrelation scattering length and is related to the fringe period as shown in Fig. 3 .

\subsubsection{Autocorrelation Length Background}

In the dilute, non-interacting sphere model, the autocorrelation length, $\xi$, can be thought of as the diameter of the particle size causing scattering in the DF images. In the case of the HZB Talbot-Lau interferometer, the autocorrelation length is set at a fixed scattering length whereas the far-field interferometer is able to probe a wide range of scattering lengths. The scattering length for the HZB Talbot-Lau interferometer was $1.97 \mu \mathrm{m}$ for the sample upstream of the G1 grating and is computed by:

$$
\begin{aligned}
\xi(z) & =\frac{\lambda z^{\prime}}{p_{g}} \\
z^{\prime} & =\left(L_{1}+L_{2}-z\right) \frac{L_{2}}{L_{1}}
\end{aligned}
$$

where the source to $\mathrm{G} 1$ distance, $L_{1},=4.5 \mathrm{~m}$, the $\mathrm{G} 2$ to detector distance, $L_{2},=22.7 \mathrm{~mm}$, the period of the phase grating, $p_{g},=4.0 \mu \mathrm{m}$, the wavelength, $\lambda,=0.35 \mathrm{~nm}$, and the sample to detector distance, $\mathrm{z},=66 \mathrm{~mm}$. The distances are further defined in Fig. 1 in Ref. [36].

The scattering length for the NIST far-field interferometer ranged from $0.60 \mu \mathrm{m}$ to $1.99 \mu \mathrm{m}$ and is computed by:

$$
\xi(z)=\frac{\lambda z D}{\left(L_{1}+D+L_{2}\right) p_{g}^{2}}
$$

where the distances are defined in Fig. 2 and have values of $L_{1}=2.3 \mathrm{~m}, L_{2}=2.3 \mathrm{~m}, D=26 \mathrm{~mm}, p_{g 1}=2.4 \mu \mathrm{m}, \lambda$ $=0.54 \mathrm{~nm}$, and $z$ ranged from $0.477 \mathrm{~m}$ to $1.537 \mathrm{~m}$.

\footnotetext{
${ }^{3}$ https://www.ncnr.nist.gov/resources/activation/
} 


\subsubsection{Autocorrelation Calculations}

Autocorrelation plots were generated using a weighted nonlinear least squares fitting package. DF images for each sample were filtered using a median filter $(r=2.0)$ and finally a mean filter $(r=3.0)$. Histograms of areas of interest (fractured neck region in middle of sample, non-fractured good region on left side of sample) revealed the average DF signal and standard deviation. The standard deviation was divided by the square root of the number of pixels in the area of interest to obtain a measure of uncertainty for the DF signal. All of the $\xi$, DF, and uncertainty values were explored for the five different areas of interest.

\section{Results and Discussion}

\subsection{Neutron Attenuation Imaging}

The first experiment to observe crack formation is the traditional neutron imaging of the $3 \mathrm{~mm}$ dogbone samples. An attenuation volume rendering of all 6 samples and a slice view are seen in Figure 4. The volume was generated by tomographic imaging of the three AM and three conventional dogbones in the field of view.
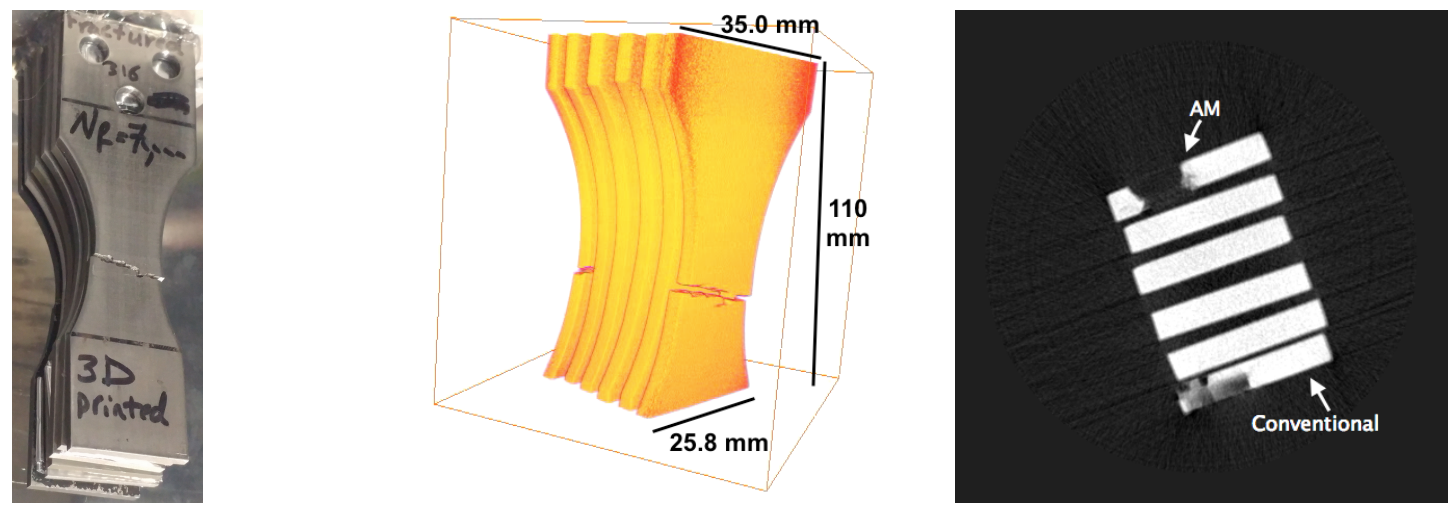

Figure 4: Experimental pictures of the three AM and three conventional SS316 dogbones (left), a volume rendering (middle), and a top down view slice of the crack regions (right).

In the attenuation volume rendering of all six samples, no crack formation can be observed in the pristine or half-life samples. Traditional neutron imaging shows changes in attenuation values between materials with different properties. Since the pristine, half-life, and fractured samples were all composed of SS316, changes in attenuation between the pristine and fractured samples were not anticipated nor observed. Even with rotating the samples to different orientations, only the fractured samples show their respective crack locations due to an air gap between both sides of the fracture. In the slice view on the right, the only visible cracks are in the already fractured AM and conventional samples. This experiment proves the need for alternative imaging methods like Bragg edge imaging or grating-based interferometry to obtain crystallographic/scattering information unobtainable with attenuation imaging.

\subsection{Neutron Bragg Edge Spectroscopy and Imaging}

Neutron Bragg edge imaging was explored for possible crack detection by intensity changes between a pristine, half-life, and fractured sample. Bragg edge spectra and imaging results for the SS316 dogbones are shown below. In the case of Bragg edge experiments, only neutron transmission is utilized (no gratings 
are used). An interesting difference in the wavelength-resolved signal was observed between conventionally machined and additively manufactured SS316. Figure 5 shows the SLM steel possesses a different crystallographic structure than that of the conventional steel.
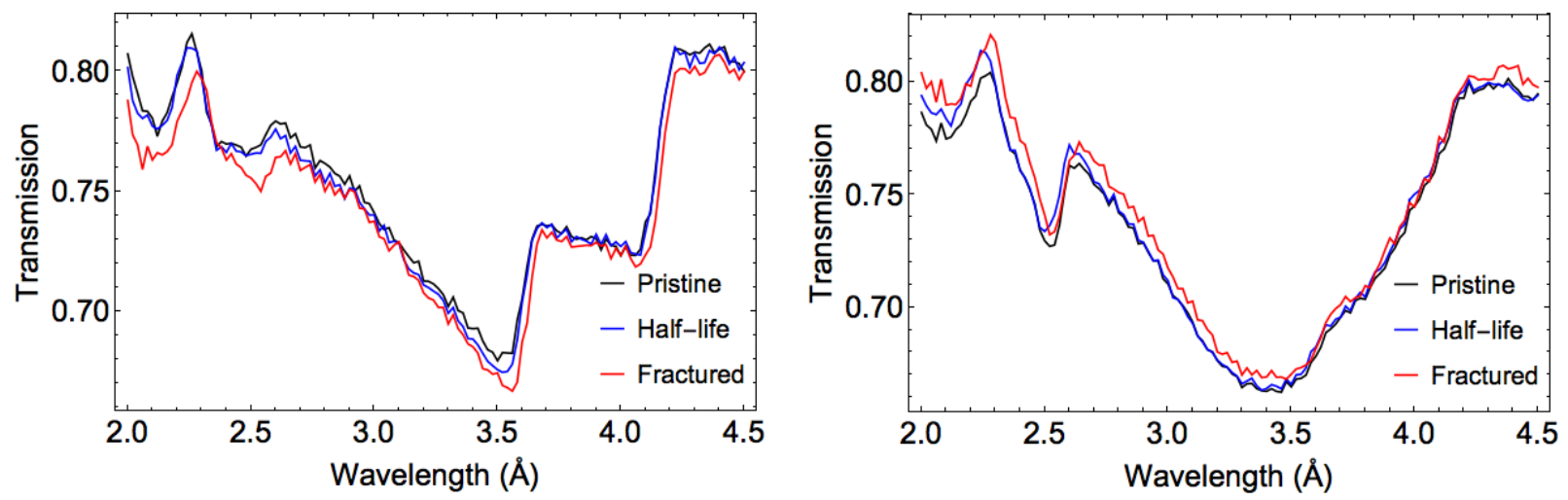

Figure 5: On the left are the Bragg edge spectra for the AM pristine, half-life, and fractured samples. On the right are the spectra for the conventional dogbones.

In the conventional sample, the spectra are similar to $\alpha$-martensite [21]. In comparison to the conventional dogbones, the AM samples have peaks at $0.365 \mathrm{~nm}$ and $0.42 \mathrm{~nm}$, which are indicative of a different crystalline form, namely austenite [22]. The strong peak at $0.23 \mathrm{~nm}$ represents the bcc (211) martensite phase in the conventional samples while the peak at $0.265 \mathrm{~nm}$ appears similar to a virgin fcc (311) phase for austenite [40]. Based on Woracek et al.[22], under high tension, the austenite phase can be fully transformed to martensite. The formation of martensite in the conventional samples, made from plates $3 \mathrm{~mm}$ in thickness, is in part due to the plastic flow encountered during the fabrication process. When performing Bragg edge imaging, crack formation in the half-life AM dogbone was not observed (Fig. 6).

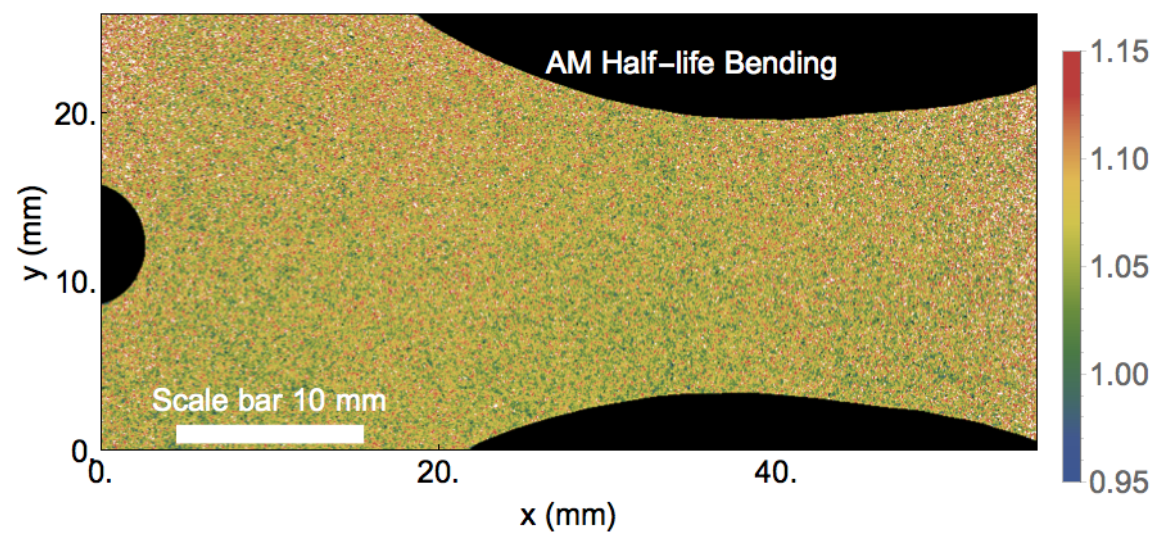

Figure 6: This neutron attenuation image was taken by diving the region from $0.22 \mathrm{~nm}$ to $0.26 \mathrm{~nm}$ by $0.38 \mathrm{~nm}$ to $0.41 \mathrm{~nm}$ for the AM half-life sample. The color bar scale on the right represents the neutron transmission through the sample. Areas of higher transmission are indicated in red while areas of lower transmission are indicated in blue. Unfortunately despite intensity differences, crack formation was not observed.

Crack formation observed in the AM Bragg images was anticipated to be observed when dividing the areas from $0.22 \mathrm{~nm}$ to $0.26 \mathrm{~nm}$ by $0.38 \mathrm{~nm}$ to $0.41 \mathrm{~nm}$. However, neither region showed evidence of crack formation. Although Bragg-edge spectroscopy may have the potential to provide information on crack for- 
mation, our results indicate that the strain distribution along the beam direction does not provide this information. We now turn our attention to the dark-field interferometry images which provide information on scattering structures around the 1 micrometer length scale.

\subsection{Neutron Talbot-Lau Interferometry}

The HZB CONRAD2 Talbot-Lau interferometer was configured for $\xi=1.97 \mu \mathrm{m}$. The optimal sample/interferometer orientation was anticipated to have the fatigued samples perpendicular to the scattering plane as defined by the Talbot-Lau gratings. In these imaging experiments, vertical gratings implied the dogbones needed to be horizontal to show possible crack formation in the middle of the neck region. Projections of conventional $3 \mathrm{~mm} \mathrm{SS316}$ samples showing crack formation on the top and bottom of the neck region are shown in Figure 7. In Figures 7 through 9 , the scale bars on the right of each image represent the amount of scattering from the dogbones. Values closer to 1.0 (blue/black) indicate less scattering while values closer to 0.0 (red) represent more scattering.
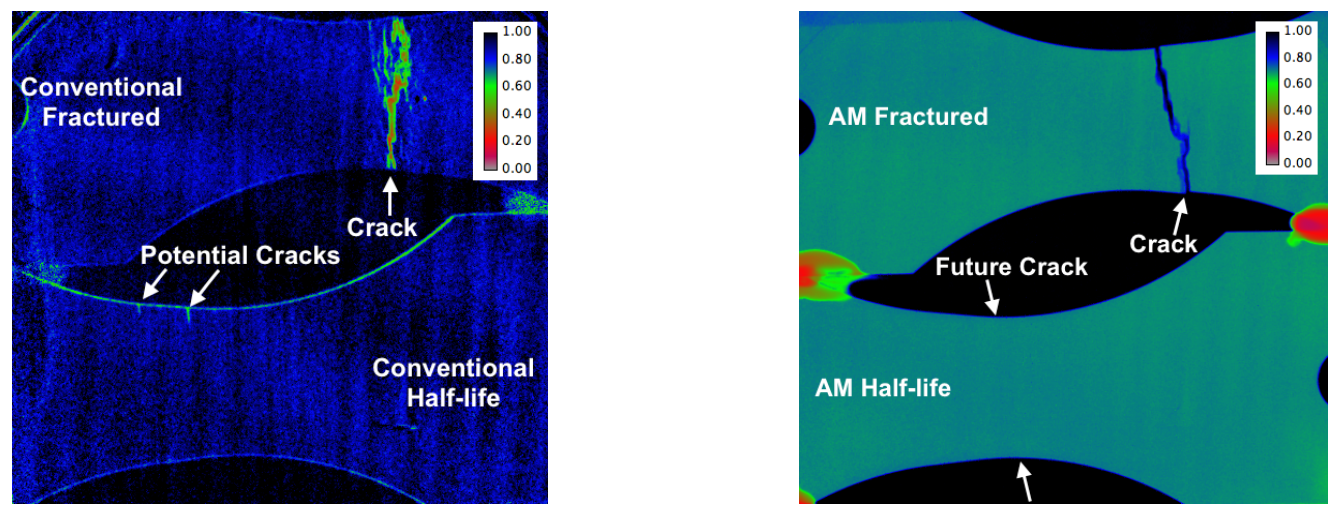

Figure 7: Processing of the conventional fractured and half-life dogbones (left) and the AM fractured and half-life dogbones (right). The "future crack" is located based on additional bending fatigue applied after neutron imaging. After failure, the dogbone was photographed and the neutron and optical images aligned.

In Figure 7, two larger cracks are visible on the top portion and two small cracks on the bottom portion of the conventional sample. When the sample was rotated on its side, the crack was estimated to be $1 \mathrm{~mm}$ in depth of this $3 \mathrm{~mm}$ sample. While the scattering length of $1.97 \mu \mathrm{m}$ was beneficial for observing crack formation in conventional samples, a different scattering length is needed to observe crack formation in AM samples. When the AM half-life and fractured samples were imaged, no differences were observed in the dark-field values. This implies that the scattering length probed was too large to detect any changes from porous microstructures within the AM material. For this reason, far-field interferometry was performed in $\xi$ scanning mode to find an appropriate scattering length in the AM dogbones.

\subsection{Far-Field Interferometry Studies on Pristine and Fatigued Dogbones}

Shown in Fig. 8 is a comparison of AM fractured and pristine samples at two unique scattering lengths, $\xi=607 \mathrm{~nm}$ and $\xi=956 \mathrm{~nm}$, with stress axis perpendicular to the scattering plane. The far-field interferometry dark-field imaging shows evidence of small sized defects in the "pristine" sample. Also, distinct banding along the dogbone is visible at the scattering length of $\xi=607 \mathrm{~nm}$. In the fractured dogbone, the scattering 
intensity is focused at the site of fracture. Bending fatigue is affecting the scattering sizes at the sub-micron scale.
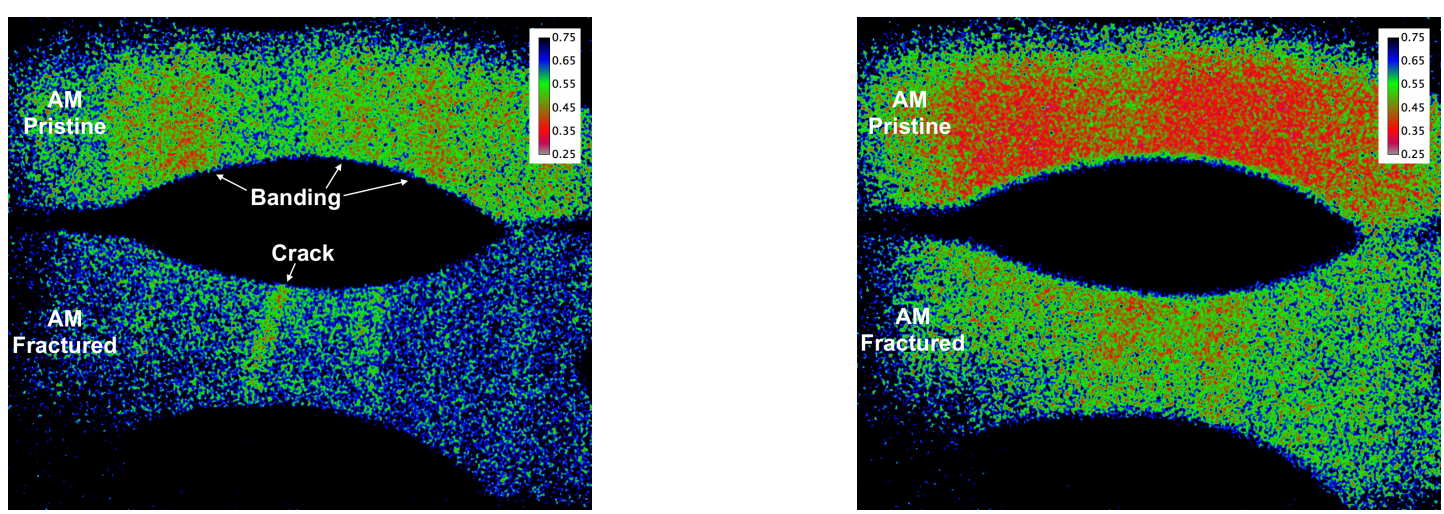

Figure 8: Far-field interferometry dark-field images at $\xi=607 \mathrm{~nm}$ (left) and $956 \mathrm{~nm}$ (right). The pristine AM shows irregular porosity across the build with six differing regions of scattering intensity. With the stress needed to fracture, fatigue conditioning has localized the porosity for both fractured and stressed.

Fig. 9 shows the progression of increased scattering in the neck region as $\xi$ increases. At $0.72 \mu \mathrm{m}$, there is limited scattering in the neck region of the sample. This implies that the average scattering site is larger than $0.72 \mu \mathrm{m}$. At $\xi$ of $0.84 \mu \mathrm{m}$, we observe a higher concentration of vertical scattering (red) in the middle of the neck. At $0.96 \mu \mathrm{m}$ and $1.07 \mu \mathrm{m}$, we observe that the neck region has reached "saturation", meaning the image includes scattering from all values up to $1.07 \mu \mathrm{m}$. Once a sample reaches this saturation point, there are no observable features of larger size. For this reason, we conclude that $0.84 \mu \mathrm{m}$ is a good autocorrelation length scale to probe for these AM samples.
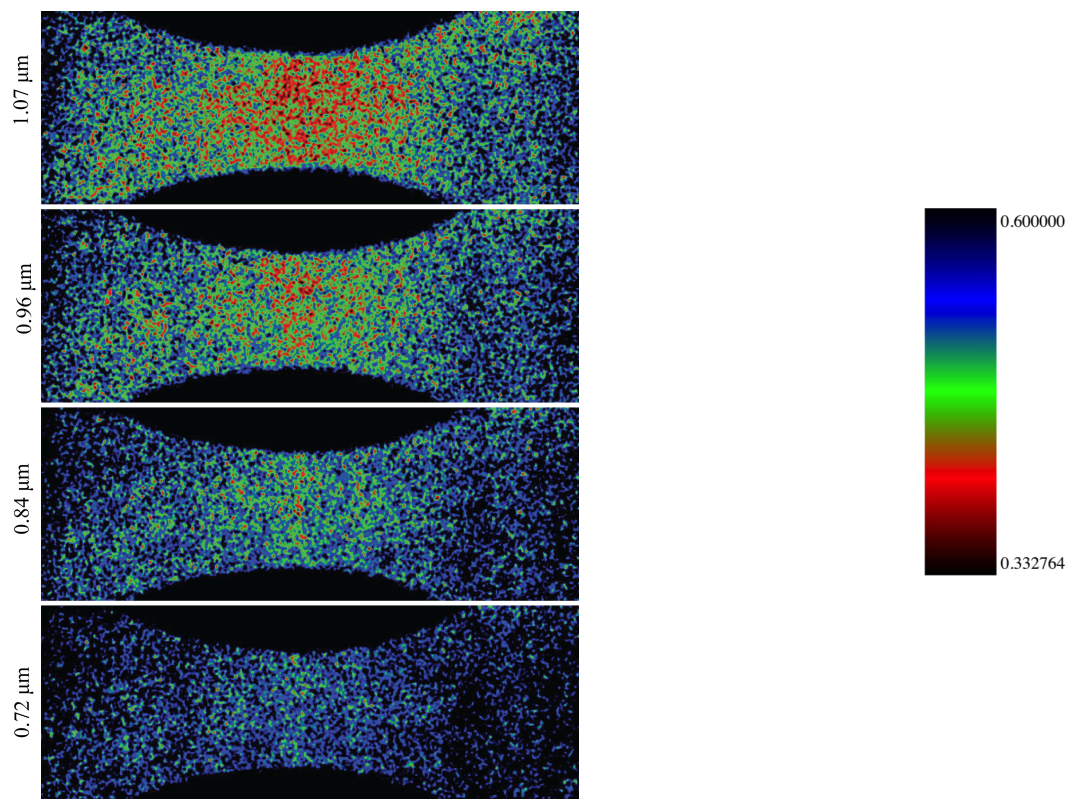

Figure 9: The $3 \mathrm{~mm}$ SLM SS316L AM half-life dogbone imaged at four different sub-micron scattering lengths. The dark-field images were acquired with pixel sizes of $28 \mu \mathrm{m}$, median filtered $(\mathrm{r}=3)$ and mean filtered $(\mathrm{r}=2)$. Presumptive crack formation can begin to be seen at $\xi=0.84 \mu \mathrm{m}$ and is more pronounced at $\xi=0.96 \mu \mathrm{m}$ to $1.07 \mu \mathrm{m}$. At the interferometer settings for larger $\xi$ values, geometric blur is interfering with crack localization. 
From the dark-field images as a function of $\xi$, a comparison of the radius and porous volume fraction were calculated for the pristine, half-life, and fractured $3 \mathrm{~mm}$ AM samples in the neck and the "good"/grip regions (Fig. 10).

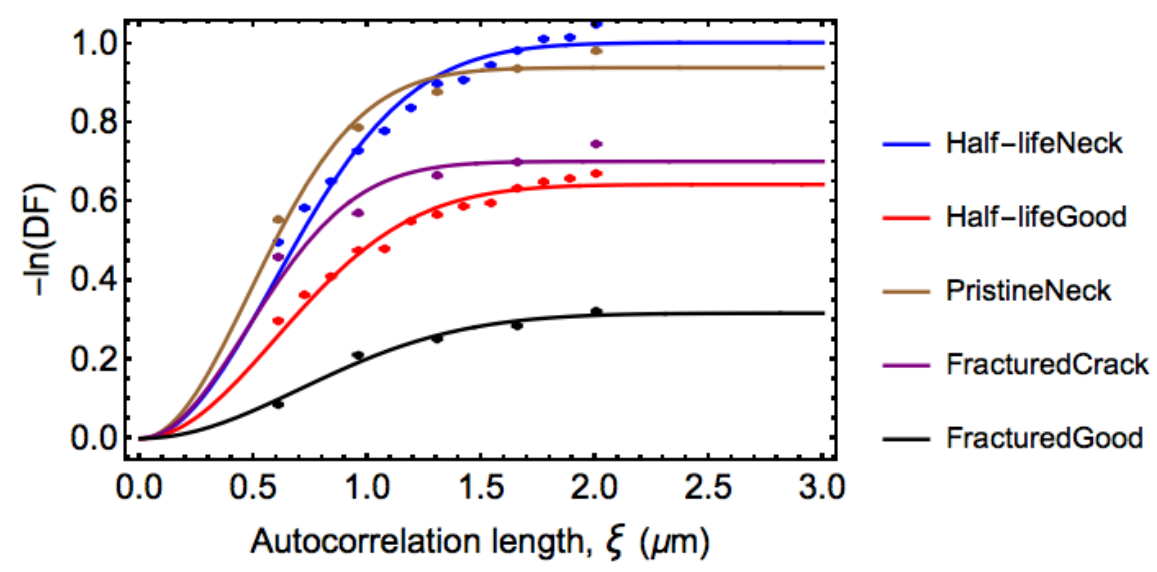

Figure 10: Plot of dark-field versus autocorrelation length for the pristine, half-life, and fractured 3 mm samples. Half-lifeNeck (blue): $\mathrm{r}=(0.881+/-0.012) \mu \mathrm{m}, \phi_{v}=\left(0.0013150+/-4.55 \times 10^{-7}\right)$. Half-lifeGood $(\mathrm{red}): \mathrm{r}=(0.893+/-0.022) \mu \mathrm{m}, \phi_{v}=(0.0008342$ $\left.+/-4.85 \times 10^{-7}\right)$. PristineNeck (brown): $\mathrm{r}=(0.721+/-0.017) \mu \mathrm{m}, \phi_{v}=\left(0.001500+/-1.00 \times 10^{-6}\right)$. FracturedCrack (purple): $\mathrm{r}=$ $(0.704+/-0.022) \mu \mathrm{m}, \phi_{v}=\left(0.001153+/-1.04 \times 10^{-6}\right)$. FracturedGood (black): $\mathrm{r}=(1.0526+/-0.101) \mu \mathrm{m}, \phi_{v}=(0.0003574+/-$ $\left.7.37 \times 10^{-7}\right)$. The reported uncertainty is the one-sigma root mean square uncertainty of the nonlinear least squares fit.

The nonlinear fitting of the curves gives estimates of the scattering site radius and the volume fraction of pores. The fitted scatterer size for the pristine sample is $721 \mathrm{~nm}$, the half-life sample is $880 \mathrm{~nm}$ to $890 \mathrm{~nm}$, and the fractured sample is $704 \mathrm{~nm}$ (neck region) to $1.05 \mu \mathrm{m}$ (good, grip region). Because the pristine AM sample is not homogeneous (where a conventionally built dogbone would be homogeneous), the dark-field signal fluctuation could cause slight errors in the expected pristine curve. The highest porous volume fraction $\left(\phi_{v}=0.001500(1)\right)$ in the pristine sample can be easily verified with Figure 8 , where the AM pristine sample has a high amount of scattering in comparison to the AM fractured sample. In the fractured sample, the higher $\phi_{v}$ value $(0.001153(1))$ occurs at the crack location rather than the outer, good region (0.0003574(7)).

Of interest between the pristine, half-life, and fractured dogbones is how the estimated particle radius size causes the scattering to decrease from the pristine to half-life to fractured samples. This likely indicates a progression from larger to smaller sized grains over the course of the fatigue testing. Based on dark-field imaging, the fractured sample particle size decreases from $1.05 \mu \mathrm{m}$ in the good region to $700 \mathrm{~nm}$ around the crack.

After imaging, the half-life conventional and AM dogbones were fatigued to fracture. The point of fracture in the conventional dogbone was at the location of the larger of the two potential cracks observed in the left image of Fig. 7. The label "Future Crack" in the right image of Fig. 7] was determined from photography, Fig. 11. Based on the results obtained through Talbot-Lau and far-field interferometry, the likelihood of observing crack formation in a dogbone before its half-life is possible. The samples used in this study were only fatigued to their half-life or fracture point, however experiments can be designed to image samples at any fatigue level, and in-situ. 


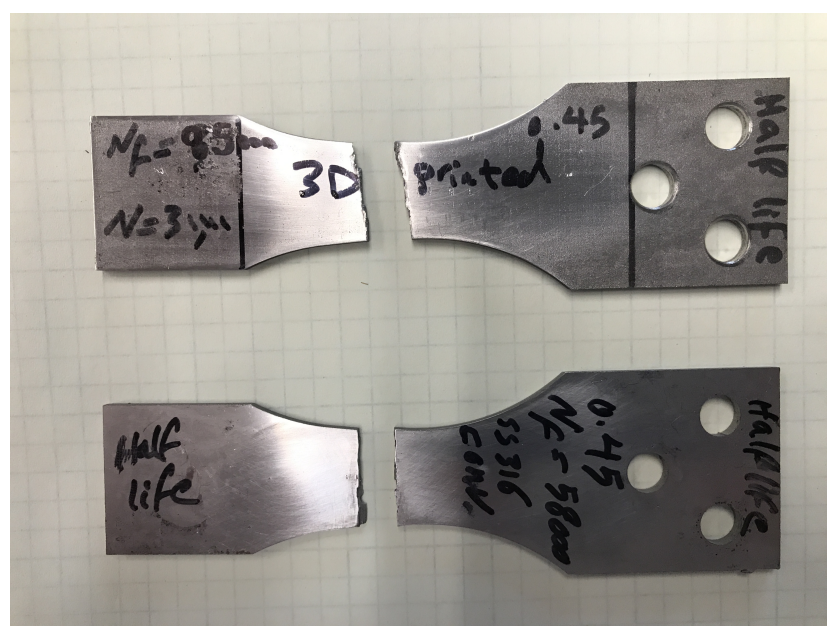

Figure 11: The half-life SLM (top) and conventional (bottom) dogbones when fatigued to fracture after neutron imaging. For the AM sample, the dark-field scattering observed throughout Fig. 9 roughly predicts the fracture. In the conventional sample, the crack occurs at the larger of the two "Potential Cracks" in the left image of Fig. 7

\subsection{SEM of Fractured AM Dogbone}

Figure 12 shows the SEM images taken on the fatigue fractured AM dogbone sample at three different locations. Spot one is very close, within $0.3 \mathrm{~mm}$, to the fracture front; Spots two and three are about 5 and $8 \mathrm{~mm}$ from the fracture front respectively. Stresses and strains in the tested samples vary at different locations, and the fracture front is usually associated with the maximum stress/strain. Our testing results reconfirm a well-documented grain refinement phenomenon caused by large strain deformation [41, 42]. Clearly, near the fracture front, a region with many fine grains is developed over the course of the fatigue tests. This supports the dark-field autocorrelation results, where small scatterers were detected near the crack, as shown in Fig. 8 for the lower sample labeled "AM Fractured".
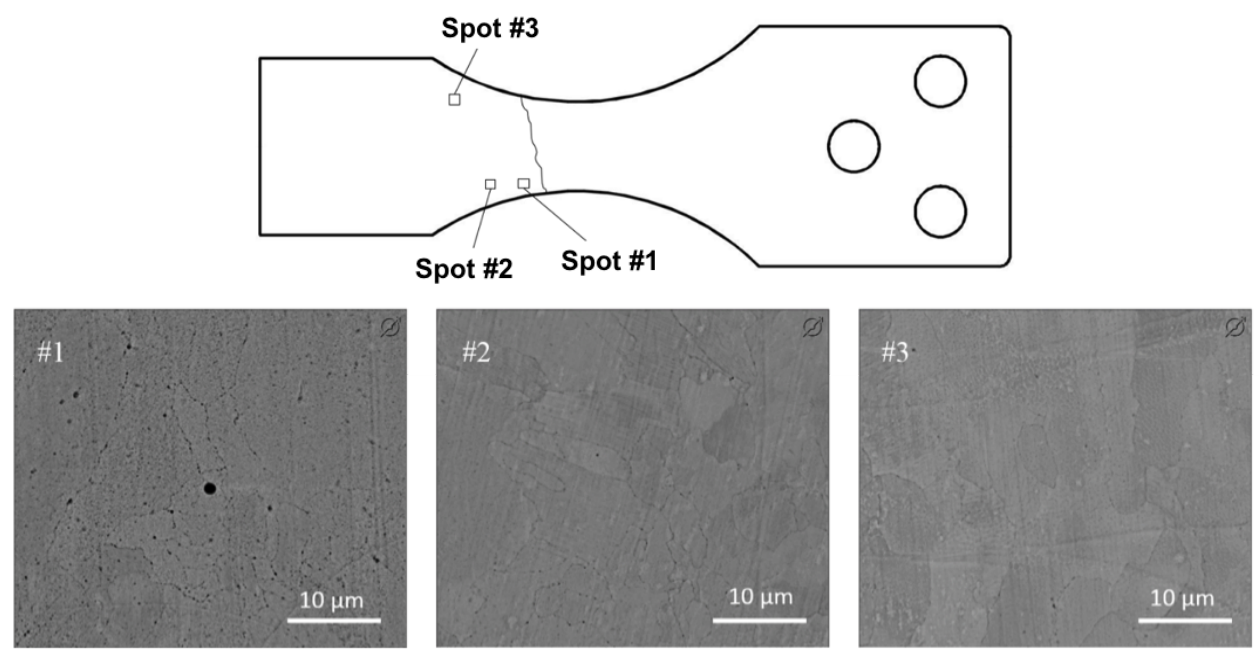

Figure 12: SEM images showing grain refinement (spot \#1) near the fracture front on the fractured AM SS316 sample. 


\section{Conclusions}

Crack formation in SLM and conventionally machined $3 \mathrm{~mm}$ thick SS316 dogbones was discovered using neutron Talbot-Lau and far-field interferometry. Traditional neutron attenuation imaging did not reveal features of interest in the AM or conventional samples, resulting in a focus on dark-field imaging obtained by grating interferometry. Neutron Bragg edge spectroscopy indicated the SLM parts were of the austenite phase rather than the originally desired $\alpha$-martensite phase. However, the Bragg imaging did not show the expected changes between pristine, half-life, and fractured samples.

Traditional neutron Talbot-Lau interferometry, with a set autocorrelation length, $\xi$ of $1.97 \mu \mathrm{m}$, revealed crack formation in the half-life and fractured conventional samples but not the AM dogbones. A microstructure of small cracks was discovered surrounding the large crack in the fractured conventional sample. In the case of the conventional half-life sample, two small cracks not visible to the human eye were observed by interferometry to penetrate $1 \mathrm{~mm}$ into the $3 \mathrm{~mm}$ thick samples.

As the Talbot-Lau interferometer did not reveal crack formation for the AM dogbones, a neutron farfield interferometer probing a wide range of autocorrelation lengths (606 nm - $1.99 \mu \mathrm{m})$ did show several features of interest. During imaging, the dark-field signal was found to change drastically for each of the AM samples. At $606 \mathrm{~nm}$, the pristine sample had inhomogeneous scattering across the neck region, likely due to a lack of fatigue conditioning. In the half-life sample, evidence of crack formation can be observed at $840 \mathrm{~nm}$ and $960 \mathrm{~nm}$ when the sample stress axis is perpendicular to the scattering plane.

In studying the dark-field images for the pristine, half-life, and fractured samples, a model of dilute, noninteracting spheres enabled extraction of the scatterer size and pore volume fraction. The pristine sample had the smallest scatterer radius near $0.72 \mu \mathrm{m}$, the fractured sample the widest range of sizes $(0.70-1.05 \mu \mathrm{m})$, and the half-life sample in-between $(0.88 \mu \mathrm{m})$. The grip regions at the ends of the half-life and fatigued samples had larger sizes in comparison to the neck regions, implying grain refinement as the samples underwent fatigue. In an ideal world, experiments to look further at crack formation will possess the low blur of TalbotLau interferometry with the wide scanning range of $\xi$ from the far-field interferometer. The combination of the two techniques can reveal microcrack location and scatterer size in both AM and conventional samples. 


\section{Acknowledgments}

AJM and LGB gratefully acknowledge support from the Louisiana Consortium for Neutron Scattering (LaCNS), funded by the US Department of Energy-EPSCoR Cooperative Agreement No. EPS-1003897 and the Louisiana Board of Regents. AJB also thanks the Charles E. Coates Memorial Fund for research travel support. HY and SMG are supported by the NSF EPSCoR Consortium for Innovation in Materials and Manufacturing (CIMM) project under award OIA-1541079. The use of the CIMM Core User Facilities (CUFs), including the LSU Shared Instrumentation Facility (SIF) and Materials, Manufacturing, Testing, and Evaluation Facility (MMTEF), is acknowledged.

\section{Competing Interests}

On behalf of all authors, the corresponding author states that there are no competing interests.

\section{References}

[1] Martins, C.M.B., Moreira, J.L., Martins, J.I. (2014) Corrosion in water supply pipe stainless steel 304 and a supply line of helium in stainless steel 316. Eng. Failure Anal. 39: 65-71.

[2] Paffumi, E., Nilsson, K.F., Szaraz, Z. (2015) Experimental and numerical assessment of thermal fatigue in 316 austenitic steel pipes. Eng. Failure Anal. 47(Part B): 312-327.

[3] Li, S.X., He, Y.N., Yu, S.R., Zhang, P.Y. (2013) Evaluation of the effect of grain size on chromium carbide precipitation and intergranular corrosion of 3161 stainless steel. Corrosion Science 66(Supplement C): $211-216$.

[4] Ahmadi, A., Mirzaeifar, R., Moghaddam, N.S., Turabi, A.S., Karaca, H.E., Elahinia, M. (2016) Effect of manufacturing parameters on mechanical properties of 3161 stainless steel parts fabricated by selective laser melting: A computational framework. Mater. Des. 112(Supplement C): 328 - 338 .

[5] Liakat, M., Khonsari, M.M. (2014) An experimental approach to estimate damage and remaining life of metals under uniaxial fatigue loading. Mater. Des. 57: 289-297.

[6] Santos, E.C., Shiomia, M., Osakada, K., Laoui, T. (2006) Rapid manufacturing of metal components by laser forming. Int. J. Mach. Tool. Manu. 46(12/13): 1459-1468. 
[7] Cunningham, R., Narra, S.P., Montgomery, C., Beuth, J., Rollett, A.D. (2017) Synchrotron-based x-ray microtomography characterization of the effect of processing variables on porosity formation in laser power-bed additive manufacturing of ti-6al-4v. JOM 69(3): 479-484.

[8] Thompson, A., Maskery, I., Leach, R.K. (2016) X-ray computed tomography for additive manufacturing: a review. Meas. Sci. Technol. 27(7): art. no. 072001.

[9] Fabrègue, D., Landron, C., Bouaziz, O., Maire, E. (2013) Damage evolution in twip and standard austenitic steel by means of 3d x ray tomography. Mater. Sci. Eng. A 579: 92-98.

[10] Wu, M.W., Chen, J.K., Lin, B.H., Chiang, P.H. (2017) Improved fatigue endurance ratio of additive manufactured ti-6al-4v lattice by hot isostatic pressing. Mater. Des. 134: 163-170.

[11] Siddique, S., Imran, M., Rauer, M., Kaloudis, M., Wycisk, E., Emmelmann, C., Walther, F. (2015) Computed tomography for characterization of fatigue performance of selective laser melted parts. Mater. Des. 83: 661-669.

[12] Wu, Y., Liu, W.H., Wang, X.L., Ma, D., Stoica, A.D., Nieh, T.G., He, Z.B., Lu, Z.P. (2014) In-situ neutron diffraction study of deformation behavior of a multi-component high-entropy alloy. Appl. Phys. Lett. 104(5): art. no. 051910.

[13] Peetermans, S., King, A., Ludwig, W., Reischig, P., Lehmann, E.H. (2014) Cold neutron diffraction contrast tomography of polycrystalline material. Analyst 139(22): 5765-5771.

[14] Peetermans, S., Lehmann, E.H. (2016) Simultaneous neutron transmission and diffraction imaging investigations of single crystal nickel-based superalloy turbine blades. NDT \& E Int. 79: 109-113.

[15] Santisteban, J.R., Daymond, M.R., James, J.A., Edwards, L. (2006) Engin-x: a third-generation neutron strain scanner. J. Appl. Crystallogr. 39: 812-825.

[16] Szost, B.A., Terzi, S., Martina, F., Boisselier, D., Prytuliak, A., Pining, T., Hofmann, M., Jarvis, D.J. (2016) A comparative study of additive manufacturing techniques: Residual stress and microstructural analysis of clad and waam printed ti-6al-4v components. Mater. Des. 89: 559-567.

[17] Phan, T.Q., Levine, L.E., Lee, I.F., Xu, R., Tischler, J.Z., Huang, Y., Langdon, T.G., Kassner, M.E. (2016) Synchrotron x-ray microbeam diffraction measurements of full elastic long range internal strain 
and stress tensors in commercial-purity aluminum processed by multiple passes of equal-channel angular pressing. Acta Materialia 112: $231-241$.

[18] Strobl, M., Sales, M., Plomp, J., Bouwman, W.G., Tremsin, A.S., Kaestner, A., Pappas, C., Habicht, K. (2015) Quantitative neutron dark-field imaging through spin-echo interferometry. Sci. Rep. 5: art. no. 16576.

[19] Brooks, A.J., Ge, J., Kirka, M.M., Dehoff, R.R., Bilheux, H.Z., Kardjilov, N., Manke, I., Butler, L.G. (2017) Porosity detection in electron beam-melted ti-6al-4v using high-resolution neutron imaging and grating-based interferometry. Prog. Addit. Manuf. 2(3): 125-132.

[20] Steuwer, A., Santisteban, J.R., Withers, P.J., Edwards, L., Fitzpatrick, M.E. (2003) In situ determination of stresses from time-of-flight neutron transmission spectra. J. Appl. Crystallogr. 36: 1159-1168.

[21] Woracek, R., Penumadu, D., Kardjilov, N., Hilger, A., Boin, M., Banhart, J., Manke, I. (2014) 3d mapping of crystallographic phase distribution using energy-selective neutron tomography. Adv. Mater. (Weinheim, Ger.) 26(24): 4069-4073.

[22] Dabah, E., Pfretzschner, B., Schaupp, T., Kardjilov, N., Manke, I., Boin, M., Woracek, R., Griesche, A. (2017) Time-resolved bragg-edge neutron radiography for observing martensitic phase transformation from austenitized super martensitic steel. J. Mater. Sci. 52(6): 3490-3496.

[23] Pfeiffer, F., Grunzweig, C., Bunk, O., Frei, G., Lehmann, E., David, C. (2006) Neutron phase imaging and tomography. Phys. Rev. Lett. 96(21): art. no. 215505.

[24] Pushin, D.A., Sarenac, D., Hussey, D.S., Miao, H., Arif, M., Cory, D.G., Huber, M.G., Jacobson, D.L., LaManna, J.M., Parker, J.D., Shinohara, T., Ueno, W., Wen, H. (2017) Far-field interference of a neutron white beam and the applications to noninvasive phase contrast imaging. Phys. Rev. A 95: art. no. 043637.

[25] Miao, H., Panna, A., Gomella, A.A., Bennett, E.E., Znati, S., Chen, L., Wen, H. (2016) A universal moire effect and application in x-ray phase-contrast imaging. Nat. Phys. 12: 830-834.

[26] Betz, B., Harti, R.P., Strobl, M., Hovind, J., Kaestner, A., Lehmann, E., Van Swygenhoven, H., Gruenzweig, C. (2015) Quantification of the sensitivity range in neutron dark-field imaging. Rev. Sci. Instrum. 86(12): art. no. 123704. 
[27] Cunningham, R., Narra, S.P., Ozturk, T., Beuth, J., Rollett, A.D. (2016) Evaluating the effect of processing parameters on porosity in electron beam melted ti-6al-4v via synchrotron $\mathrm{x}$-ray microtomography. JOM 68(3): 765-771.

[28] Swanson, S., ed.: ASTM Special Technical Publication, No. 566: Handbook of Fatigue Testing. ASTM International, West Conshohocken, PA, (1974).

[29] Gruenzweig, C., David, C., Bunk, O., Kohlbrecher, J., Lehmann, E., Lai, Y.W., Schaefer, R., Roth, S., Lejcek, P., Kopecek, J., Pfeiffer, F. (2010) Visualizing the propagation of volume magnetization in bulk ferromagnetic materials by neutron grating interferometry (invited). J. Appl. Phys. 107(9): art. no. 09d308.

[30] Kardjilov, N., Hilger, A., Manke, I., Woracek, R., Banhart, J. (2016) Conrad-2: the new neutron imaging instrument at the helmholtz-zentrum berlin. J. Appl. Crystallogr. 49(1): 195-202.

[31] Kardjilov, N., Hilger, A., Manke, I. (2016) Conrad-2: Cold neutron tomography and radiography at ber ii (v7). JLSRF 2: A98.

[32] Manke, I., Kardjilov, N., Schafer, R., Hilger, A., Strobl, M., Dawson, M., Grunzweig, C., Behr, G., Hentschel, M., David, C., Kupsch, A., Lange, A., Banhart, J. (2010) Three-dimensional imaging of magnetic domains. Nat. Commun. 1: art. no. 125.

[33] Hussey, D.S., Brocker, C., Cook, J.C., Jacobson, D.L., Gentile, T.R., Chen, W.C., Baltic, E., Baxter, D.V., Doskow, J., Arif, M. (2015) A new cold neutron imaging instrument at nist. Phys. Procedia 69: $48-54$.

[34] Marathe, S., Assoufid, L., Xiao, X., Ham, K., Johnson, W.W., Butler, L.G. (2014) Improved algorithm for processing grating-based phase contrast interferometry image sets. Rev. Sci. Instrum. 85(1): art. no. 013704.

[35] Wen, H., Bennett, E.E., Hegedus, M.M., Carroll, S.C. (2008) Spatial harmonic imaging of x-ray scattering-initial results. IEEE Trans. Med. Imaging 27(8): 997-1002.

[36] Strobl, M. (2014) General solution for quantitative dark-field contrast imaging with grating interferometers. Sci. Rep. 4: art. no. 7243. 
[37] Lynch, S.K., Pai, V., Auxier, J., Stein, A.F., Bennett, E.E., Kemble, C.K., Xiao, X., Lee, W.K., Morgan, N.Y., Wen, H.H. (2011) Interpretation of dark-field contrast and particle-size selectivity in grating interferometers. Appl. Opt. 50(22): 4310-4319.

[38] Prade, F., Yaroshenko, A., Herzen, J., Pfeiffer, F. (2015) Short-range order in mesoscale systems probed by x-ray grating interferometry. EPL 112(6): art. no. 68002.

[39] Andersson, R., van Heijkamp, L.F., de Schepper, I.M., Bouwman, W.G. (2008) Analysis of spin-echo small-angle neutron scattering measurements. J. Appl. Crystallogr. 41: 868-885.

[40] Woracek, R., Penumadu, D., Kardjilov, N., Hilger, A., Boin, M., Banhart, J., Manke, I. (2015) Neutron bragg edge tomography for phase mapping. Physics Procedia 69(Supplement C): 227 - 236. Proceedings of the 10th World Conference on Neutron Radiography (WCNR-10) Grindelwald, Switzerland October 510, 2014.

[41] Guo, Q., Yan, H., Chen, Z., Zhang, H. (2007) Grain refinement in as-cast az80 mg alloy under large strain deformation. Materials Characterization 58(2): $162-167$.

[42] Lu, J., Luo, K., Zhang, Y., Cui, C., Sun, G., Zhou, J., Zhang, L., You, J., Chen, K., Zhong, J. (2010) Grain refinement of ly2 aluminum alloy induced by ultra-high plastic strain during multiple laser shock processing impacts. Acta Materialia 58(11): 3984 - 3994. 